\title{
Effect of black and white sesame cake extracts on retarding lipid oxidation in catfish fat
}

\author{
Hong K. Lieu, Tuan Q. Dang \\ Department of Food Technology, International University, VNU-HCMC, Linh Trung w., Thu Duc Dist., Ho Chi Minh City, Vietnam
}

Email address:

dqtuan@hcmiu.edu.vn (T. Q. Dang)

\section{To cite this article:}

Hong K. Lieu, Tuan Q. Dang. Effect of Black and White Sesame Cake Extracts on Retarding Lipid Oxidation in Catfish Fat. Journal of Food and Nutrition Sciences. Special Issue: Food Processing and Food Quality. Vol. 3, No. 1-2, 2015, pp. 39-44.

doi: $10.11648 /$ j.jfns.s.2015030102.17

\begin{abstract}
The aim of this research was to study the possibility for preservation of catfish fat by using sesame cake extracts (SCE) as a source of natural antioxidants. The SCEs were obtained by extraction of black and white sesame cakes with methanol. Catfish (Pangasius hypophthalmus) fat was mixed with the black and white SCE at different concentrations and stored at room temperature (RT) and $60^{\circ} \mathrm{C}$, in comparison with the synthetic antioxidant -BHT at concentration of $200 \mathrm{ppm}$. The results showed that the total phenolic content (TPC) in black SCE was $1386.3 \pm 89.6 \mathrm{mgGAE} / 100 \mathrm{~g}$ dw (dry weight) and in white SCE $1318.5 \pm 68.7 \mathrm{mgGAE} / 100 \mathrm{~g} \mathrm{dw}$. The free-radical scavenging capacity, determined by the 1, 1-diphenyl-2picrylhydrazyl (DPPH) free-radical scavenging assay, of the black and white SCE were significantly lower than that of BHT and ascorbic acid. The $\mathrm{IC}_{50}$ values of the black, white SCE samples, BHT and ascorbic acid were 817, 833, 31 and $7 \mathrm{mg} / \mathrm{L}$, respectively. However, both the white and black SCE showed a strong effect on retarding lipid oxidation in catfish fat, which was comparable to that of BHT at $200 \mathrm{ppm}$. The free fatty acid values (FFA) and peroxide values (PV) of the catfish fat samples treated with the black and white SCEs at a concentration of $400 \mathrm{ppm}$, were lower than $6.0 \mathrm{mg} \mathrm{KOH} / \mathrm{g}$ fat and 16 $\mathrm{meq} / \mathrm{kg}$ fat, respectively, when stored at both room temperature and $60^{\circ} \mathrm{C}$ up to 42 days.
\end{abstract}

Keywords: Butylated Hydroxyltoluene, Catfish Fat, Natural Antioxidant, Sesame Cake Extract, Total Phenolic Content

\section{Introduction}

Catfish fat is an important by-product from catfish processing, which accounts for more than $20 \%$ of the total fish mass. Catfish fat has a potential to become an important foodstuff because it is rich in poly-unsaturated fatty acids with significant omega-3 content (Ho \& Paul, 2009). However, it is susceptible to oxidation (rancidity), leading to quick deterioration of quality during storage. Fat rancidity with formation of unwanted components in food is the main reason of degradation of the nutritional quality of food. The primary and secondary products of lipid oxidation are detrimental to health. In the body, excess production of free radicals may cause damage to proteins, cell membranes and biological components, which leads to many biological changes, such as DNA damage, ageing, heart disease and cancer (Ladikos \& Lougovois, 1990).

Addition of antioxidants is a method for increasing shelflife of fat and fat-containing foods. Synthetic antioxidants may be implicated in many health risks, including cancer and carcinogenesis. Butylated hydroxyanisole (BHA) and butylated hydroxytoluene (BHT) have restricted use in food (Ito et al., 1986), while the use of tertiary butyl hydroquinone (TBHQ) is not permitted in many countries (Shahidi, 2000). Hence, there is a tendency towards the use of natural antioxidants of plant origin to replace synthetic antioxidants.

Sesame seeds (Sesamum indicum L.) contain around 50\% sesame oil, which is regarded as high-quality vegetable oil. The presence of natural antioxidants of lignan type accounts for both the superior stability of sesame oil and the beneficial physiological effects of sesame (Hwang, 2005). Sesame cake, a by-product from oil extraction industry obtained after removal of oil is mainly used as a feed ingredient. The antioxidants remained in cake are extracted with different solvents such as ethanol, ethyl acetate, methanol, methanolwater (v/v) and water (Reshma et al., 2012). Sesame cake extracts (SCE) contain various lignans that are phenolic compounds with antioxidant capacity (Suja et al., 2005a). SCEs display bio-activities such as effect on polyunsaturated fatty acid metabolism, hypocholesterolemic and anti-cancer (Hwang, 2005) or decrease in lipid peroxidation (Ikeda et al., 
2003). Antioxidant potential of SCE was used in stabilization of sunflower and soybean oils, in which, antioxidant activity of the SCE was stronger than that of BHT and BHA, but weaker than THBQ (Mohdaly et al., 2011). Suja and coworkers (2004) found that SCE at $100 \mathrm{ppm}$ were effective in lowering $\mathrm{PV}$, diene value and $\mathrm{p}$-anisidine value in vegetable oils and showed a better antioxidant effect than BHT at 200 ppm. In the lipid model systems, crude SCE at 100 and 200 ppm were effective and showed antioxidant activity comparable to BHT at $200 \mathrm{ppm}$, while the purified SCE showed comparable or better activity at 200 ppm or much lower levels (Suja et al., 2005b). Konsoula \& LiakopoulouKyriakides (2010) reported that the ethanolic extract of sesame seed (defatted) was very effective in protecting vegetable oil (olive, soybean, sunflower and corn) from oxidation.

Reports on the use of natural antioxidants to prevent lipid oxidation in catfish fat were rare. Green tea extract (GTE) was applied in catfish fat and it was found that a dose of GTE at 1600 ppm was as effective as BHT at $200 \mathrm{ppm}$ (Dang \& Tran, 2013). There is a need for investigation on using of different natural antioxidant sources for preservation of foodstuff in general and for fatty products in particular. Therefore, the objective of this research is to investigate the application of sesame cake extract (black and white) as a potential natural antioxidant source for preservation of catfish fat.

\section{Materials and Methods}

\subsection{Materials and Chemicals}

Dried sesame seeds (both black and white) and cat fish were purchased from local markets.

Gallic acid, Folin-Ciocalteau reagent were acquired from Merk (Germany), DPPH and BHT from Sigma (US). Organic solvents (methanol, hexane, chloroform, acetic acid, diethyl ether, ethanol) and chemicals for titration including Potassium Iodide (KI), $\mathrm{KOH}, \mathrm{Na}_{2} \mathrm{~S}_{2} \mathrm{O}_{3} 0.01 \mathrm{~N}$, and $\mathrm{Na}_{2} \mathrm{CO}_{3}$ were of analytical grade and provided from a local chemical agent.

\subsection{Methods}

\subsubsection{Extraction and Purification of Extracts from Sesame Seed Cake}

$50 \mathrm{~g}$ of sesame seed (black or while) were ground through a $500 \mu \mathrm{m}$ sieve and defatted by extraction with $200 \mathrm{~mL}$ hexane (3 times). The obtained sesame seed cake was washed three times with $500 \mathrm{~mL}$ distilled water in a beaker, with stirring at $50^{\circ} \mathrm{C}$ for $30 \mathrm{~min}$. The cake was then filtered and dried at $50^{\circ} \mathrm{C}$ in an oven. Extraction of the dried cake (black or white sesame) was done for $10 \mathrm{~g}$ of the material with $150 \mathrm{~mL}$ methanol in an Erlenmeyer flask with shaking for $24 \mathrm{~h}$ at RT. The extract was obtained after solvent removal under vacuum by using a rotary evaporator (model Stuart RE $300 \mathrm{DB}, \mathrm{UK}$ ) at $50^{\circ} \mathrm{C}$. The dried extract was redissolved in methanol making a $16,000 \mathrm{ppm}$ stock solution and stored at $-20{ }^{\circ} \mathrm{C}$ for further use.

\subsubsection{Extraction of Catfish fat From Fish}

The method was described elsewhere (Dang \& Tran, 2013). The fat was collected from fish chest, chopped up and blended well in a blender. Then it was cooked (melt down) in a microwave at $95-100^{\circ} \mathrm{C}$ for $5-7 \mathrm{~min}$. The melting fat was centrifuged at 3,500 rpm for $15 \mathrm{~min}$. The catfish fat on the top of the tube was decanted and stored in a freezer.

\subsubsection{Total Phenolic Content}

Total phenolic content (TPC) of the dried sesame extract was determined spectrophotometrically by using FolinCiocalteu reagent and Gallic acid standard solution, according to AOAC method 9.110. A volume $(0.1 \mathrm{~mL})$ of the sesame extract solution was accurately transferred to a 100 $\mathrm{mL}$ beaker containing $75 \mathrm{~mL}$ distilled water. $5 \mathrm{~mL}$ of FolinCiocalteu reagent and $10 \mathrm{~mL}$ of $\mathrm{Na}_{2} \mathrm{CO}_{3}$ solution $(7.5 \%)$ were added to the flask then diluted to $100 \mathrm{~mL}$. The mixture was shaken for $1 \mathrm{~min}$, allowed to stand at RT for $30 \mathrm{~min}$. The absorbance was measured at $760 \mathrm{~nm}$ (3 times) by a spectrophotometer (model Genesys 10S, Thermo Scientific, USA). The result was expressed as $\mathrm{mg}$ Gallic acid equivalents (mg GAE)/g dw (dry weight) of plant materials.

\subsubsection{DPPH Radical Scavenging Assay}

The antioxidant capacity of the sesame cake extract was measured by using the DPPH radical scavenging assay in comparison to BHT and ascorbic acid (AA) as performed elsewhere (Dang \& Tran, 2013). Sesame cake extract, BHT, and AA solutions were prepared at concentrations in a range from 20 to $80 \mathrm{mg} / \mathrm{L}$. A volume $(3 \mathrm{~mL})$ of DPPH in methanol $(20 \mathrm{mg} / \mathrm{L})$ was mixed with $3 \mathrm{~mL}$ of the SCE solution (or BHT, AA solutions). The reaction mixture was allowed to stand at RT in the dark for $30 \mathrm{~min}$. Absorbance was measured at $515 \mathrm{~nm}$, and the control was prepared by mixing $3 \mathrm{~mL}$ methanol with $3 \mathrm{~mL}$ of the DPPH solution. The percent inhibition of free radical was calculated: $\%$ inhibition $=\left[\left(\mathrm{A}_{0}\right.\right.$ $\left.\left.-A_{s}\right) / A_{0}\right]^{*} 100$; where $A_{s}$ is absorbance of sample and $A_{0}$ absorbance of the control.

\subsubsection{Free Fatty Acid Value}

Free fatty acids (FFA) values were measured in the catfish fat samples before and after treatment with the SCEs or BHT against the blank (no treatment) by using titration method against $\mathrm{KOH}$ in the presence of phenolphalein indicator (method AOCS Ca 5a-40). The results were expressed in $\mathrm{mg}$ of $\mathrm{KOH}$ required to neutralize the free fatty acids present in $1 \mathrm{~g}$ of sample.

FFA value $(\mathrm{mg} \mathrm{KOH} / \mathrm{g}$ of sample $)=[(\mathrm{A}-\mathrm{B}) \times \mathrm{N} \times 56.1] / \mathrm{W}$

Where: A - mL of standard alkali used in the titration; B $\mathrm{mL}$ of standard alkali used in titrating the blank; $\mathrm{N}$ normality of the standard alkali; W - grams of sample.

The SCEs were applied in the catfish fat at 50, 100, 200, $400 \mathrm{ppm}$ while BHT at $200 \mathrm{ppm}$. Samples were taken in several periods during storage at RT and $60^{\circ} \mathrm{C}$ up to 42 days. 


\subsubsection{Peroxide Value}

Peroxide values (PV) were measured by using Iodometric titration method (AOCS Cd8-53). This assay is based on the oxidation of the iodide ion $\left(\mathrm{I}^{-}\right)$by hydroperoxides $(\mathrm{ROOH})$, in which a saturated solution of potassium iodide is added to catfish fat sample to react with hydroperoxides. The liberated iodine $\left(\mathrm{I}_{2}\right)$ is then titrated with a standardized solution of sodium thio-sulfate, using starch as an endpoint indicator.

$$
\text { Peroxide value }=\left(\mathrm{V}_{1}-\mathrm{V}_{0}\right) \times \mathrm{N} \times 1000 / \mathrm{m}_{\text {sample }(\mathrm{g})}
$$

Where: $V_{1}$ - volume of thio-sulfate solution required to titrate the sample $(\mathrm{mL}) ; \mathrm{V}_{0}$ - volume of thio-sulfate solution required to titrate the blank determination $(\mathrm{mL}) ; \mathrm{N}$ normality of the sodium thio-sulfate solution; $\mathrm{m}$ - mass of sample (g).

The PV was reported as milliequivalents of oxygen per kilogram of catfish fat sample (meq $/ \mathrm{kg}$ ).

\section{Results and Discussion}

\subsection{Extraction Yield and TPC of the SCEs}

The TPC of black and white SCE was 1386.3 and 1318.5 mgGAE/100g dw, respectively, and they were not significantly different. Mohdaly et al. (2011) reported the TPC of $194 \mathrm{mg}$ GAE/100g dw in the SCE, which was possibly obtained from cold press, since it still contained a lot of oil. Another study reported that TPC value of SCE was $543.8 \mathrm{mg}$ GAE$/ 100 \mathrm{~g} \mathrm{dw}$ for purified extract (Suja et al., $2005 b$ ), quite lower than the values in this research. Jeong and co-workers (2004) reported that by heat treatment a content of TPC in the SCE solution could reach to $87.4 \mu \mathrm{M}$ (tannic acid), which was by calculation equivalent to the

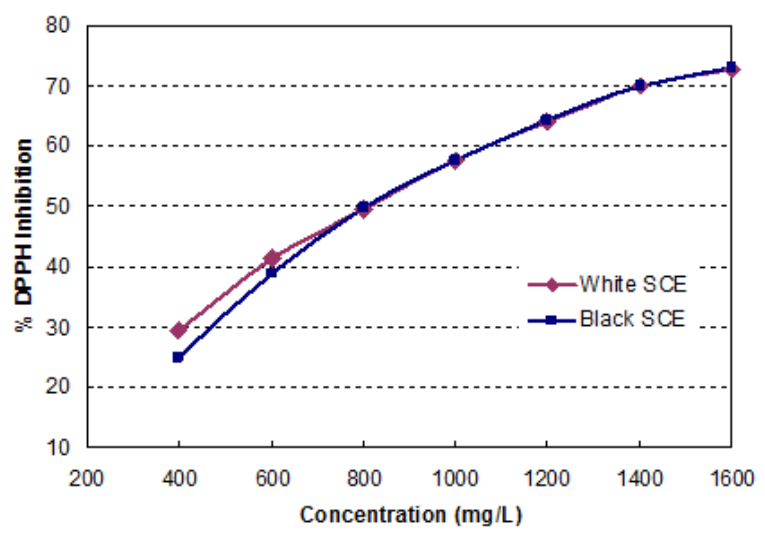

(a) content of $1487 \mathrm{mg} \mathrm{GAE} / 100 \mathrm{~g}$, quite close to the results in this study.

The results also displayed that the sesame cakes are good source of phenolic compounds, which could be obtained by solvent extraction. Among different solvent systems and conditions for extraction of phenolic compounds from SCE, methanol was found be the most efficient for extracting the antioxidant compounds (Reshma et al., 2013). In this study, the extraction yield from dried SCE was in a range of $3.66 \pm$ $0.21 \%$ and $3.78 \pm 0.19 \% \mathrm{dw}$ for back and white SCE, respectively (Table 1).

Table 1. Extraction yield, TPC and IC50 values for SCES

\begin{tabular}{llll}
\hline & Extraction Yield (\%, w/w) & TPC (mg GAE/100g) & IC50 (mg/L) \\
\hline BSCW & $3.66 \pm 0.21$ & $1386.3 \pm 89.6$ & 817.4 \\
WSCE & $3.78 \pm 0.19$ & $1318.5 \pm 68.7$ & 833.1 \\
\hline
\end{tabular}

\subsection{Antioxidant Capacity of Sesame Cake Extracts}

The antioxidant capacity of the SCEs, BHT and ascorbic acid (AA) was evaluated by DPPH radical scavenging assay and expressed as percent of DPPH inhibition (Fig. 1). The results were expressed as $\mathrm{IC}_{50}$ values (substrate concentration to produce $50 \%$ reduction of the DPPH), calculated from the regression lines of the $\%$ antioxidant capacity. The $\mathrm{IC}_{50}$ values for the black, white SCE, BHT and AA were 817.4, $833.1,31.0$ and $6.9 \mathrm{mg} / \mathrm{L}$, respectively, as calculated from the regression lines (Table 1). The $\mathrm{EC}_{50}$ value is inversely proportional to the antioxidant capacity. The radical scavenging capacity of AA was 4 times higher than that of BHT, of which in turn was nearly 26 times higher than that of black SCE. The radical scavenging power of black SCE was not significantly different from that of white SCE.

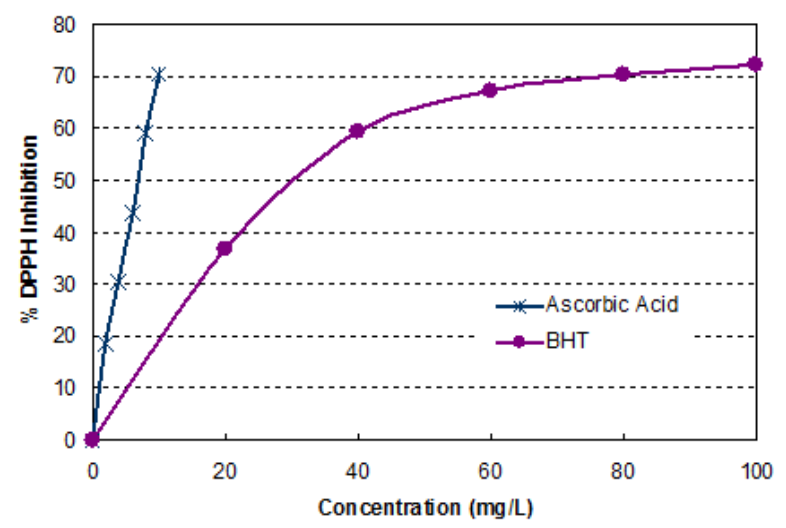

(b)

Fig 1. Antioxidant activity of black and white SCE (a), and AA and BHT (b)

There is a high correlation between TPC and the antioxidant activity (Shahidi et al. 2006). Phenolic compounds are widely distributed in plant materials, including oilseeds such as sesame seeds. The antioxidative activity of the SCE are attributed to lignans (Kumar, 2009), making them a potential source of natural antioxidants.

\subsection{Retardation of Lipid Oxidation in Catfish fat by Sesame Cake Extracts}

\subsubsection{Free Fatty Acid Values}

FFA indices (mg KOH/g) of the catfish fat samples, treated with black, white SCE or BHT, stored at RT or $60^{\circ} \mathrm{C}$ were 
measured during a period of 42 days as presented in Fig. 2 and 3.

The initial FFA index of the cat fish fat sample was about $4.2 \mathrm{mg} \mathrm{KOH} / 1 \mathrm{~g}$ fat. Abdulkadir et al. (2010) reported the FFA indices in fat from 5 fresh water fish species in a range of 5.04-8.40 mg KOH/g. However, the FFA level as an indicator of fat rancidity increased steadily with prolonging storage time.

According to Aidos et al. (2003), during storage at $15^{\circ} \mathrm{C}$ for $72 \mathrm{~h}$, the FFA of herring oil increased four times from 0.8 to $3.2 \%$ (equivalent to FFA from 16 to $64 \mathrm{mg} \mathrm{KOH} / \mathrm{g}$ ). The rate of increase depends on environmental conditions such as

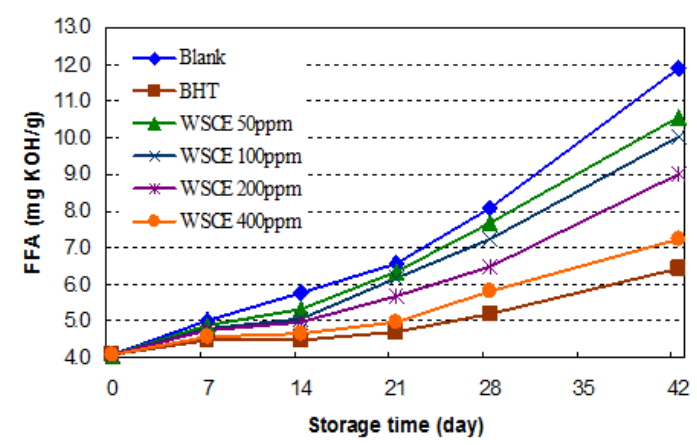

(a) temperature, light, oxygen as well as the type of fat. In this study, the FFA indices of the cat fish fat increased just 2.92 and 3.01 times at RT and $60^{\circ} \mathrm{C}$, respectively, during a period of 42 days. By adding SCE to fish fat, the rate of FFA increase was reduced, however, the effect depends on the dosage of SCE. At concentrations of SCE up to $200 \mathrm{ppm}$, the FFA indices were significantly higher that that at $400 \mathrm{ppm}$ of SCE or $200 \mathrm{ppm}$ of BHT. Both black and white SCE at 400 ppm demonstrated the same effect as BHT at $200 \mathrm{ppm}$ in retarding production of FFA in cat-fish fat. They all kept the FFA values well below $6.0 \mathrm{mg} \mathrm{KOH} / \mathrm{g}$ fat up to 42 days of storage even at $60^{\circ} \mathrm{C}$.

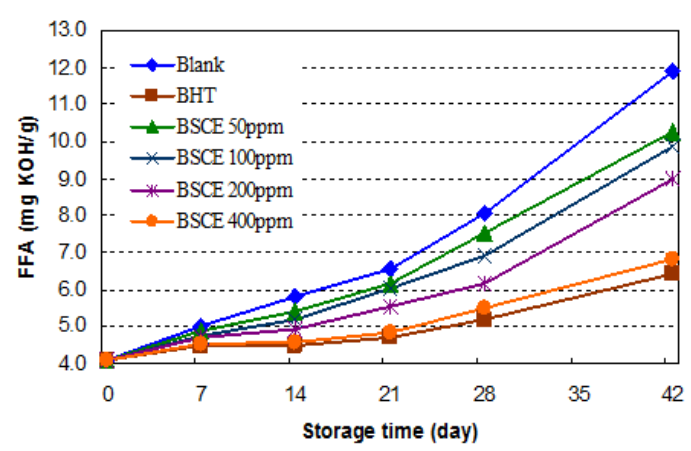

(b)

Fig. 2. FFA indices in cat-fish fat treated with different antioxidants at RT: (a) with white SCE and (b) with black SCE

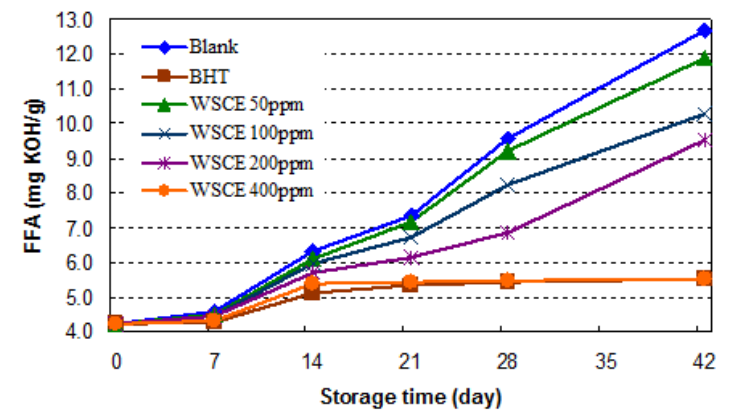

(a)

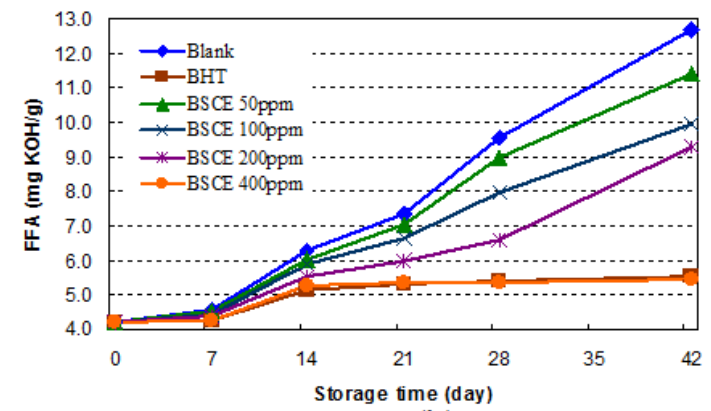

(b)

Fig 3. FFA indices in cat-fish fat treated with different antioxidants at $60^{\circ} \mathrm{C}$ : (a) with white SCE and (b) with black SCE

\subsubsection{Peroxide Values}

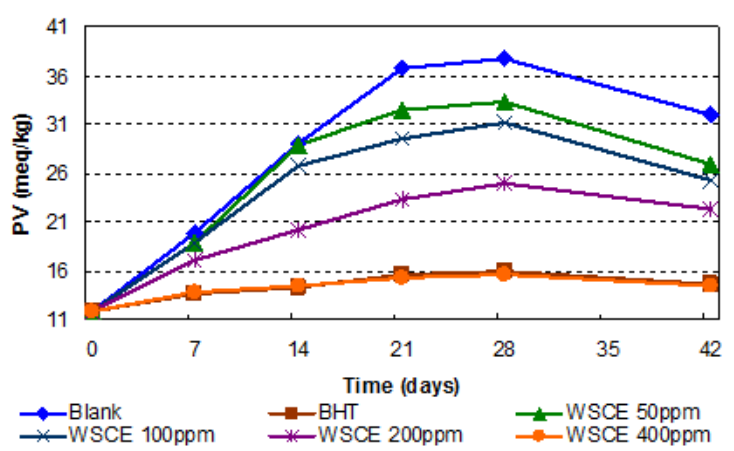

(a)

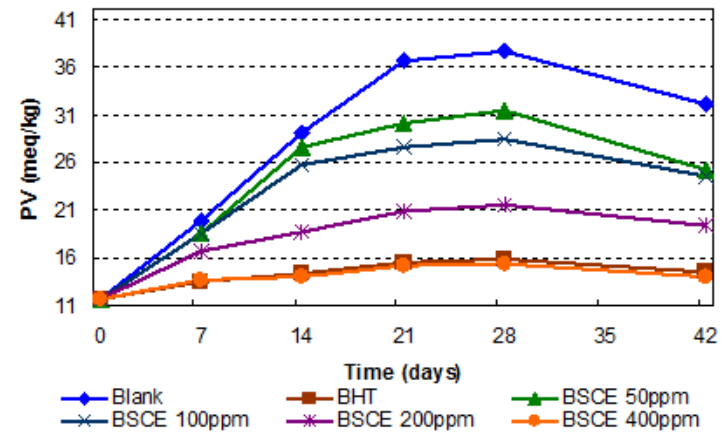

(b)

Fig 4. Peroxide values in cat-fish fat treated with different antioxidants at RT: (a) with white SCE and (b) with black SCE 


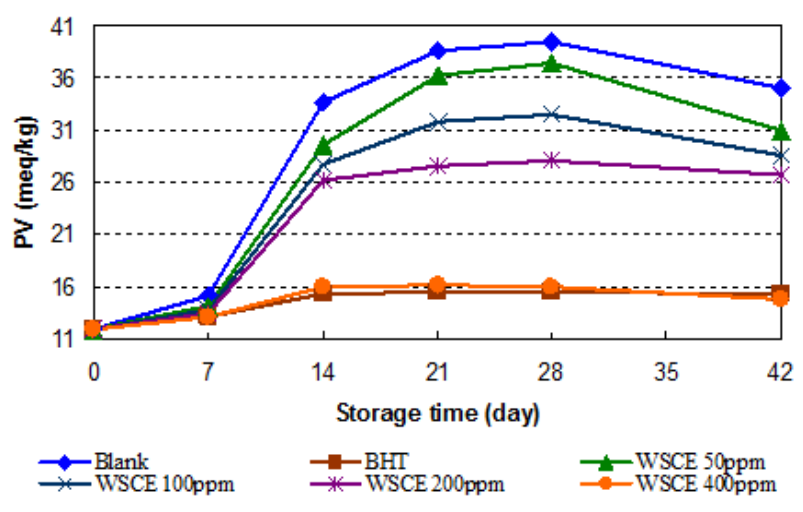

(a)

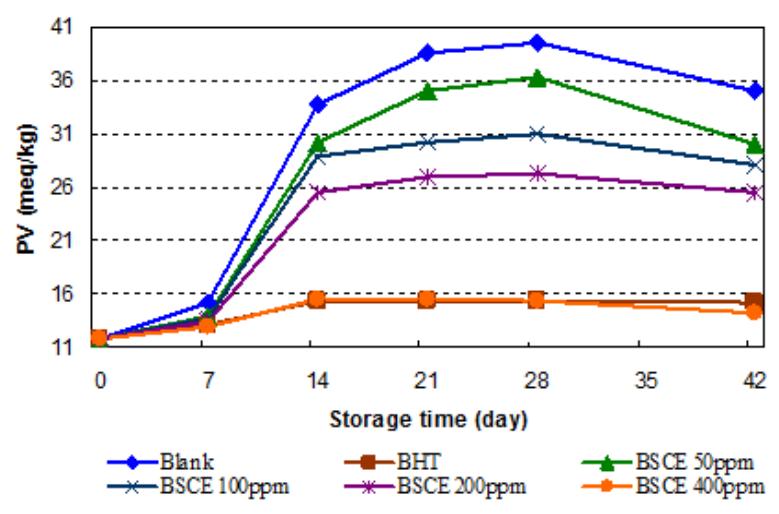

(b)

Fig 5. Peroxide values in cat-fish fat treated with different antioxidants at $60^{\circ} \mathrm{C}$ : (a) with white SCE and (b) with black SCE

The PVs (meq $/ \mathrm{kg}$ ) in the cat-fish fat samples, treated with black, white SCE and BHT, stored at RT or $60^{\circ} \mathrm{C}$ were measured during a period of 42 days, as showed in Fig. 4 and 5.

During the first four weeks of storage, PV indices of all samples containing black and white SCE at concentrations 50 , 100 , and $200 \mathrm{ppm}$ increased quickly, indicating that the effect on retarding of peroxide formation was insignificant. Moreover, oxidative process of the control samples (samples without adding antioxidants) occurred very quickly and intensively, that the PV indices increased from 11.9 to more than $36 \mathrm{meq} / \mathrm{kg}$. During this stage different internal reactions occurred. After 28 days, there was the tendency of decline in PVs for all samples. The reason may be a quenching of free radicals or peroxides were intermediates in the lipid oxidation process, and thus they decomposed after a period of time.

However, at a concentration of 400 ppm of black or white SCE, the effect was significant and comparable to that of BHT at $200 \mathrm{ppm}$, both at RT and $60^{\circ} \mathrm{C}$. Up to 42 days, the PV in cat-fish fat samples was kept below $16 \mathrm{meg} / \mathrm{kg}$. In a previous research, a dose of polyphenol-rich green tea extract (GTE) at 1600ppm showed the same effect on retardation of lipid oxidation in catfish fat as BHT at 200 ppm (Dang \& Tran, 2013). It appeared that the SCE is more effective than GTE in fat preservation. In addition, both black and white SCE showed same effect on catfish fat with non significant difference at $\mathrm{RT}$ and $60^{\circ} \mathrm{C}$.

\section{Conclusions}

Both black and white SCE were a good source of phenolic compounds. They expressed significant effect on the retardation of lipid rancidity in cat fish fat. The TPC and radical scavenging capacity of both black and white SCE were not significantly different. The application of SCE at $400 \mathrm{ppm}$ was as effective as BHT at $200 \mathrm{ppm}$ in cat fish fat at both RT and $60^{\circ} \mathrm{C}$ up to 42 days. Therefore, the SCE can be a good source of natural antioxidant and they can be used as an alternative to synthetic antioxidants for the preservation of fat-rich foods and feeds.

\section{References}

[1] Abdulkadir, M., Abubakar, G. I., \& Mohammed, A. (2010). Production and characterization of oil from fishes. ARPN Journal of Engineering and Applied Sciences, 5(7), 769-776.

[2] Aidos, I., Padt, A. V. D., Boom, R. M., \& Luten, J. B. (2003). Quality of crude fish oil extracted from herring byproducts of varying states of freshness. Journal of Food Science, 68(2), 458-465.

[3] Dang, Quoc Tuan and Tran, Thi Van Anh (2013). Preservation of catfish fat by using polyphenol-rich extract from green tea (Camellia sinensis). Journal of Science and Technology, 51(5C), 366-370.

[4] Ho, B. T. \& Paul, D. R. (2009). Fatty acid profile of Tra catfish (Pangasius hypophthalmus) compared to Atlantic salmon (Salmo solar) and Asian seabass (Lates calcarifer). International Food Research Journal, 16, 501-506.

[5] Hwang, L. S. (2005). Sesame oil. Bailey's Industrial Oil and Fat Products, p.537-576.

[6] Ikeda, S., Kagaya, M., Kobayashi, K., Tohyama, T., Kiso, Y., Higuchi, N., \& Yamashita, K. (2003). Dietary sesame lignans decrease lipid peroxidation in rats fed docosahexaenoic acid. Journal of Nutritional Science and Vitaminology, 49(4), 270276.

[7] Ito, N., Hirose, M., Fukushima, S., Tsuda, H., Shirai, T., \& Tatematsu, M. (1986). Studies on antioxidants: their carcinogenic and modifying effects on chemical carcinogenesis. Food and Chemical Toxicology, 24(10), 10711082 .

[8] Jeong, S. M., Kim, S. Y., Kim, D. R., Nam, K. C., Ahn, D. U., $\&$ Lee, S. C. (2004). Effect of seed roasting conditions on the antioxidant activity of defatted sesame meal extracts. Journal of Food Science, 69(5), C377-C381.

[9] Kumar, Mahendra C. H. (2009). Bioactivity and bioavailability of lignan from sesame (Sesamum indicum. L). Doctoral thesis, University of Mysore.

[10] Konsoula, Z., \& Liakopoulou-Kyriakides, M. (2010). Effect of endogenous antioxidants of sesame seeds and sesame oil to the thermal stability of edible vegetable oils. LWT-Food Science and Technology, 43(9), 1379-1386. 
[11] Ladikos, D., \& Lougovois, V. (1990). Lipid oxidation in muscle foods: A review. Food Chemistry, 35(4), 295-314.

[12] Mohdaly, A. A., Smetanska, I., Ramadan, M. F., Sarhan, M. A., \& Mahmoud, A. (2011). Antioxidant potential of sesame (Sesamum indicum) cake extract in stabilization of sunflower and soybean oils. Industrial Crops and Products, 34(1), 952959.

[13] Reshma, M. V., Namitha, L. K., Sundaresan, A., \& Ravi Kiran, C. (2012). Total phenol content, antioxidant activities and $\alpha-$ glucosidase inhibition of sesame cake extracts. Journal of Food Biochemistry, 37(6), 723-731.

[14] Shahidi, F. (2000). Antioxidants in food and food antioxidants. Food/Nahrung, 44(3), 158-163.
[15] Shahidi, F., Liyana-Pathirana, C. M., \& Wall, D. S. (2006) Antioxidant activity of white and black sesame seeds and their hull fractions. Food Chemistry, 99(3), 478-483.

[16] Suja, K. P., Abraham, J. T., Thamizh, S. N., Jayalekshmy, A., \& Arumughan, C. (2004). Antioxidant efficacy of sesame cake extract in vegetable oil protection. Food Chemistry, 84(3), 393-400.

[17] Suja, K.P., Jayalekshmy, A., \& Arumughan, C. (2005a). In vitro studies on antioxidant activity of lignans isolated from sesame cake extract. Journal of the Science of Food and Agriculture, 85, 1779-1783.

[18] Suja, K. P., Jayalekshmy, A., \& Arumughan, C. (2005b). Antioxidant activity of sesame cake extract. Food Chemistry, 91(2), 213-219. 